\title{
Anti-aging effects of fenugreek cream on postmenopausal skin: A randomized controlled trial
}

\author{
Shannaz Nadia Yusharyahya ${ }^{1 *}$, Kusmarinah Bramono ${ }^{1}$, Wresti Indriatmi ${ }^{1}$, Marcel Prasetyo ${ }^{2}$, Purwantyastuti Ascobat ${ }^{3}$, Andon \\ Hestiantoro $^{4}$, Anak Agung Gde Putra Wiraguna ${ }^{5}$ \\ ${ }^{1}$ Department of Dermatology and Venereology, Faculty of Medicine, Universitas Indonesia - Dr. Cipto Mangunkusumo Hospital, Jakarta Indonesia. \\ ${ }^{2}$ Department of Radiology, Faculty of Medicine, Universitas Indonesia - Dr. Cipto Mangunkusumo Hospital, Jakarta Indonesia. \\ ${ }^{3}$ Department of Pharmacology and Therapeutic, Faculty of Medicine, Universitas Indonesia. \\ ${ }^{4}$ Department of Obstetrics and Gynecology, Faculty of Medicine, Universitas Indonesia - Dr. Cipto Mangunkusumo Hospital, Jakarta Indonesia. \\ ${ }^{5}$ Department of Dermatology and Venereology, Faculty of Medicine, Universitas Udayana - Sanglah General Hospital, Denpasar Indonesia.
}

\section{ARTICLE INFO \\ Received on: 27/04/2021 \\ Accepted on: 14/08/2021 \\ Available Online: 03/11/2021}

\section{Key words:}

Dermal thickness, fenugreek, postmenopausal skin, skin wrinkle.

\begin{abstract}
Postmenopausal hypoestrogenism is associated with skin aging, for which phytoestrogen derived from the seeds of Trigonella foenum graecum (fenugreek) is expected to be an alternative solution to reduce wrinkles and increase the thickness of postmenopausal women's skin. This study was a randomized, double-blind, controlled 12-weeks trial conducted at a general hospital in Jakarta, Indonesia, from January to November 2019. Subjects were 50 postmenopausal women divided into two groups: the intervention group was given $5 \%$ fenugreek cream and base cream was given to the placebo group. The results of the independent $t$-test showed that both groups were able to achieve statistically significant improvement in wrinkle scores on the forehead, crow's feet, and nasolabial folds which was assessed by photography scoring based on Bazin's skin aging atlas for Asian skin volume 2 but there was no significant disparity between both groups at all time points. Dermal thickness was assessed by high-resolution ultrasound GE LOGIQ E9 (18 MHz), which showed similar results for both groups with significant improvements in the 8th week compared to baseline and a significant decrease by the 12th week. No significant differences were observed in the skin wrinkle score and skin thickness after the application of fenugreek cream compared to placebo. We suspect that a concentration of 5\% was not adequate for the expected antiskin aging effects. Further studies are necessary to determine a more appropriate fenugreek concentration to permit clinical use as an antiskin aging therapy in postmenopausal women.
\end{abstract}

\section{INTRODUCTION}

As Indonesians' life expectancy increases (Badan Pusat Statistik, 2019), approximately one-third of the female lifespan will be spent in the menopausal phase. Hypoestrogenism due to menopause leads to skin aging, which will affect the population seeking dermatologists for antiaging therapies. Estrogen maintains the balance between collagen synthesis and degradation in the

${ }^{*}$ Corresponding Author

Shannaz Nadia Yusharyahya, Department of Dermatology and Venereology, Faculty of Medicine, Universitas Indonesia - Dr. Cipto Mangunkusumo Hospital, Jakarta Indonesia.E-mail: nadiayusharyahya@yahoo.com skin and is in charge of stimulating the synthesis, maturation, and turnover of collagen, as well as amplifying hyaluronic acid synthesis and retaining water. Low estrogen levels cause thinning of skin layers due to a reduction in collagen, vascularization, and moisture, along with an increase in fine wrinkles (Schmidt et al., 1996; Thornton, 2002).

One of the noninvasive methods to reduce skin aging is topical therapy, with retinoic acid being the gold standard. Other alternatives for hormonal aging treatment are topical estrogen (Manela-Azulay and Bagatin, 2009) and phytoestrogen; the latter causes fewer side effects compared to oral or topical estrogen (Kapuscinska and Nowak, 2015). Phytoestrogens are natural selective estrogen receptor modulators (Kapuscinska and Nowak, 2015; Stevenson and Thornton, 2007) and nonsteroidal chemical 
compounds derived from plants (Malaivijitnond, 2012); one, in particular, is the seeds of Trigonella foenum graecum (fenugreek) (Agustini, 2012). Several studies on fenugreek have demonstrated its benefits toward skin elasticity, moisture, and melanin concentration, but subjects involved in the studies were young males and females (Gade et al., 2015; Naveed et al., 2010; Waqas et al., 2010). Our previous in vitro research was able to show the stimulation of COL1A1 and COL3A1 production (Yusharyahya et al., 2019b) through activation of estrogen receptor (ER) $\alpha$ and ER $\beta$, particularly $\operatorname{ER} \beta$, and elucidate the optimum concentration of fenugreek required (Yusharyahya et al., 2020).

No previous studies were conducted concerning the use of fenugreek extract as a topical therapy for skin aging in postmenopausal women; thus, it is hoped for this study to be the pioneer in evaluating the effects of fenugreek extracts as a topical phytoestrogen, particularly toward the clinical improvement of postmenopausal women's skin after using fenugreek cream.

\section{METHODS}

\section{Preparation of testing material formulation}

Fenugreek cream was formulated by adding several substances, such as ceteareth-20, cetostearyl alcohol, paraffin liquidum, sunclear T40 AQX, glycerin, propanediol, euxyl PE910, perfume, and 5\% fenugreek seed extract; later, it was stored in a high-density polyethylene tube. It was produced in the Research and Development Center of a pharmaceutical company. Fenugreek plants were grown by the Center for Research and Development of Medicinal Plants in Tawangmangu, Solo. The fenugreek seed was determined by Herbarium Bogoriense, and Bidang Botani Pusat Penelitian Biologi-LIPI Bogor, and extraction using ethanol was conducted in the Agency for the Assessment and Application of Technology, Serpong. During the production process of fenugreek seed extract cream, chromatography analysis was carried out to evaluate orientin (the ingredient in fenugreek with the most active binding to ERs $\alpha$ and $\beta$ ) concentration (Yusharyahya et al., 2019), and a penetration test was conducted using the Franz diffusion cell method.

\section{Clinical trials}

This study is a double-blind, randomized controlled trial carried out at Cipto Mangunkusumo Hospital in Jakarta, Indonesia, from January to November 2019. Women who were already in their postmenopausal state for 2-8 years and had aging skin problems were included, while women with facial dermatitis, consuming hormone replacement therapy, and using any antiaging skin products were excluded. Fifty subjects then were divided equally into two groups using the block randomization method by the statistician: the intervention group was given 5\% fenugreek cream and the control or placebo group was given base cream with similar ingredients and packaging was applied daily every night. Blinding was applied to both subjects and researchers. We applied a 30-day conditioning period for all subjects before the start of this study, followed by baseline data collection of skin wrinkles and dermal thickness using skin and ultrasound examination. Followup examinations were carried out on the 4th, 8 th, and 12 th week. Skin wrinkles scores were determined by using three-position photographs juxtaposed with Bazin's skin aging atlas for Asian skin volume 2 (Bazin and Flament, 2010), which focused on three areas in the skin wrinkles on the forehead, on crow's feet, and around the nasolabial folds. The Bazin atlas defines the scoring of those areas based on the clinical manifestation of the skin wrinkles and categorizes it into group scoring. The forehead area score ranged from 0 to 8 , whereas the crow's feet and nasolabial folds area scores ranged from 0 to 6 . A higher scores indicate a worse degree of facial wrinkles. Assessment of the skin wrinkles using wrinkle scores was easy, consistent, reliable, and more practical (Zhang et al., 2017). Furthermore, the dermal thickness was measured by a radiologist using an $18 \mathrm{MHz}$ high-resolution ultrasound (HRU) GE LOGIQ E9 on the cheeks. To assure that each HRU examination was consistent, patterns were made for each subject using $15 \times 5 \mathrm{~cm}$ mica plastics which were placed on each side of the cheeks; then straight lines were drawn from the upper margin of the tragus to the lower margin of oral commissure using a board marker. A cross was marked on the middle of the line as a sign to put the transducer on the cheek. As collagen builds up approximately $80 \%$ of dermal proteins, dermal thickness is considered to be representative of dermal collagen levels (Piérard et al., 2013). The compliance of the participants was assessed by their written daily journal and weighing the remaining used cream at the end of every 4 weeks; the compliance was considered good if the cream application reached more than $75 \%$, moderate if it only reached $50 \%-70 \%$, and bad if it did not reach $50 \%$. The side effects, local and systemic symptoms that appeared aside from the objectives of the primary therapy, were acquired from the history taking, physical examinations, and participants' written daily journal. The local side effects include pruritus, burning sensation, rash, desquamation, contact dermatitis, and miliaria, while the systemic side effects consist of nausea, vomiting, cephalgia, and possible breast changes. At the end of the trial, we asked the participants whether they were satisfied with the results of the cream given, which could only be answered with "satisfied" or "not satisfied."

\section{Statistical analysis}

Data were analyzed using the Stata version 14 statistical program using unpaired $t$-test and Mann-Whitney test. Analytical results were presented using bar diagrams created with GraphPad Prism 8.0 (GraphPad Software Inc, San Diego, CA).

\section{Ethical clearance}

This study has received ethical approval from the research ethics committee of the Faculty of Medicine Universitas Indonesia and registered at clinicaltrials.gov with ID number NCT04123743. The Consolidated Standards of Reporting Trials (CONSORT) diagram is shown in Figure 1.

\section{RESULTS}

Of 50 postmenopausal subjects, one dropped out in the fenugreek group due to incomplete examination at baseline. The mean age was 54.08 years in the fenugreek group and 53.06 years in the placebo group. A vast majority of the subjects (79.2\% of the fenugreek group and $54 \%$ of the placebo group) were of senior high school educational level. Both fenugreek and placebo groups 


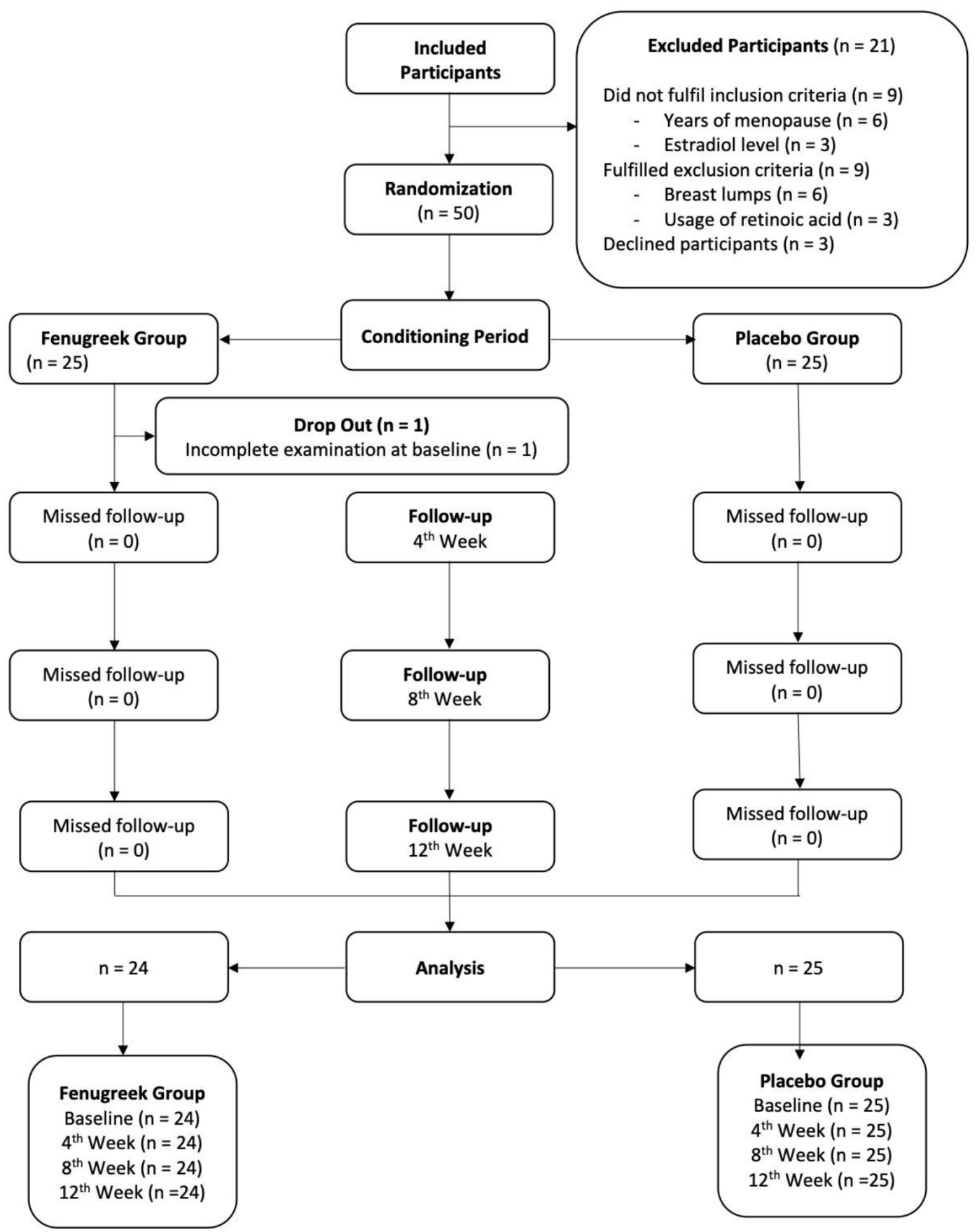

Figure 1. CONSORT diagram.

showed high average body mass indexes (BMI) of $58.3 \%$ and $60 \%$, respectively. As seen in Table 1, the sociodemographic and clinical characteristics at the baseline did not differ significantly, concluding that the subjects were adequately randomized.

The improvement in skin wrinkles (forehead wrinkles, crow's feet, and nasolabial folds) over time points of 4, 8, and 12 weeks is shown in Figures 2 and 3 and Table 2.

The decrease of forehead wrinkle scores was significantly compared to baseline after 4,8 , and 12 weeks of treatment in both placebo and fenugreek groups. Similar results were found on other areas in the skin wrinkle score, such as the crow's feet and the nasolabial fold. However, the score disparities of all areas of skin wrinkles between both groups were statistically insignificant on each follow-up visit.

Dermal thickness increased significantly between baseline and 8th week in both the placebo and fenugreek group, more so in the 8 th week compared to the 4 th week. However, in the 12th week, dermal thickness declined significantly compared to the 8th week. The difference in dermal thickness on the 4th and 8 th weeks did not differ significantly between both groups. 
Table 1. Distribution of sociodemographic and clinical characteristics among research subjects.

\begin{tabular}{cccc}
\hline Characteristics & Placebo $(\boldsymbol{n}=\mathbf{2 5})$ & Fenugreek $(\boldsymbol{n}=\mathbf{2 4})$ & $\boldsymbol{p}$-value \\
\hline Age (years old), mean (SD) & $53.60(4.92)$ & $54.08(4.21)$ & 0.714 \\
Educational background, $n$ (\%) low & $10(40)$ & $5(20.8)$ & 0.167 \\
Moderate & $14(54)$ & $19(79.2)$ & 1 \\
High BMI, $n(\%)$ & $1(4)$ & $0(0)$ & \\
underweight & $1(2)$ & $1(2)$ & 0.499 \\
Normal & $9(36)$ & $14(58.3)$ & 0.920 \\
Overweight/obese & $15(60)$ & $9.29(5.87)$ & \\
Estradiol level (pg/ml), Mean (SD) & $10.45(6.03)$ & $49.5(3.06)$ & 0.280 \\
Age at menopause (years old), & $49.6(3.77)$ & & \\
Mean (SD) & & $4.58(1.67)$ & 0.083 \\
Years of menopause (years), mean & $4(2.04)$ & & 0.589 \\
(SD) & & $4.33(1.01)$ & 0.728 \\
Forehead wrinkle score & $4.92(1.29)$ & $4.27(0.79)$ & 0.541 \\
Crow's feet score & $4.40(0.87)$ & $4.42(0.73)$ & $1.79(0.24)$ \\
Nasolabial fold score & $4.34(0.80)$ & $1.75(0.21)$ &
\end{tabular}

Data are presented in mean (standard deviation). Unpaired $t$-test was used to analyze differences between groups.
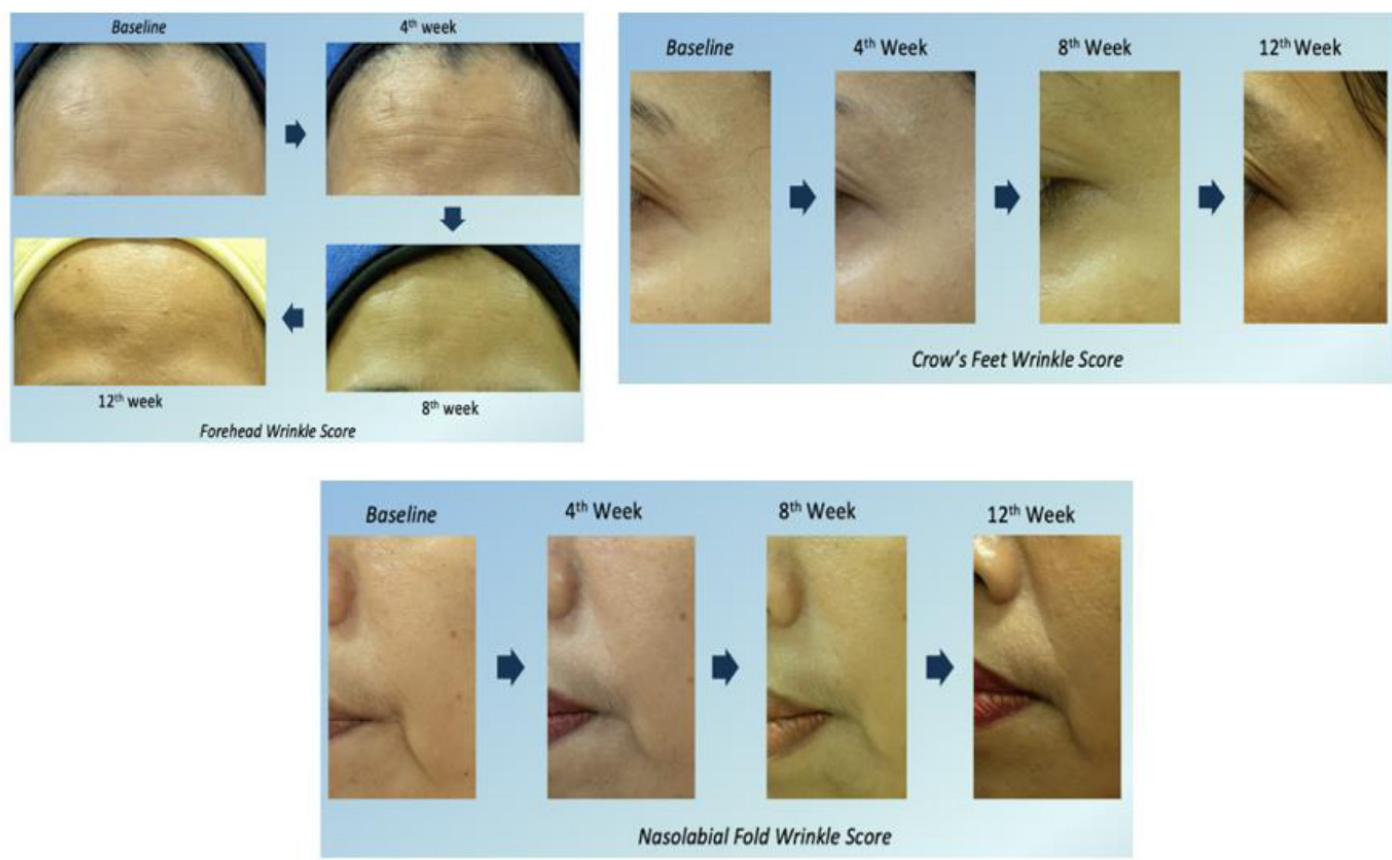

Figure 2. Skin wrinkles' scores in women given fenugreek cream.

The participant compliance and side effects that occurred throughout this study were also analyzed. The assessment of patient compliance demonstrated that $81.63 \%$ of subjects were highly compliant, $18.67 \%$ were moderately compliant, and none was noncompliant in the 4th week. The proportion of highly compliant patients improved to $83.67 \%$ in the 8 th week and $100 \%$ by the 12 th week as shown in Table 4. Moreover, pruritus was the only side effect found from both groups and experienced by in total of 14 participants on the 4th week and 6 participants on the 12th week, while none was reported on the 8 th week as seen in Table 5. There was no significant difference in the side effects between the two groups. In addition, we also assessed participants' satisfaction regarding the decrease of facial wrinkles on the 12th week. Most of the participants $(83.7 \%)$ answered that they were satisfied, while the others $(16.3 \%)$ answered that they were not satisfied as shown in Table 6 . There were no significant differences between participants' satisfaction within each group. 
Forehead Wrinkle Score

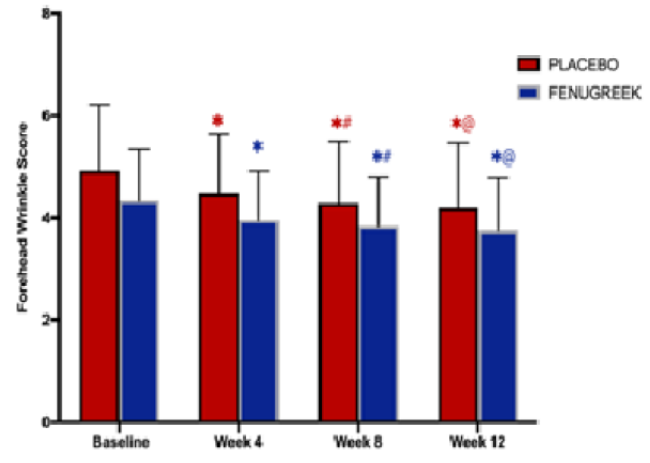

\section{Crow's Feet Score}

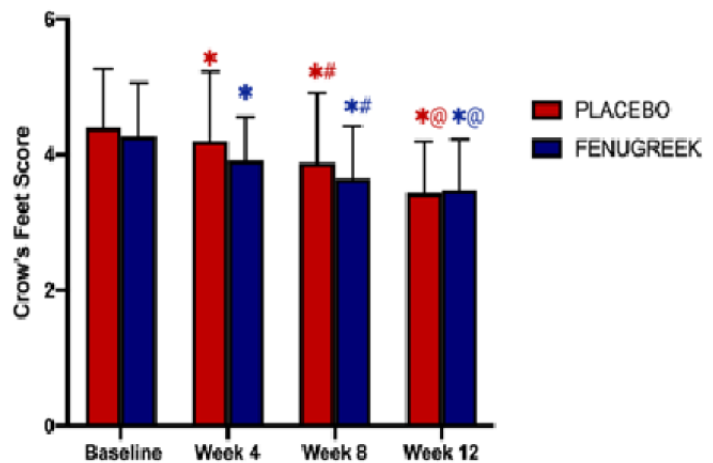

Nasolabial Fold Score

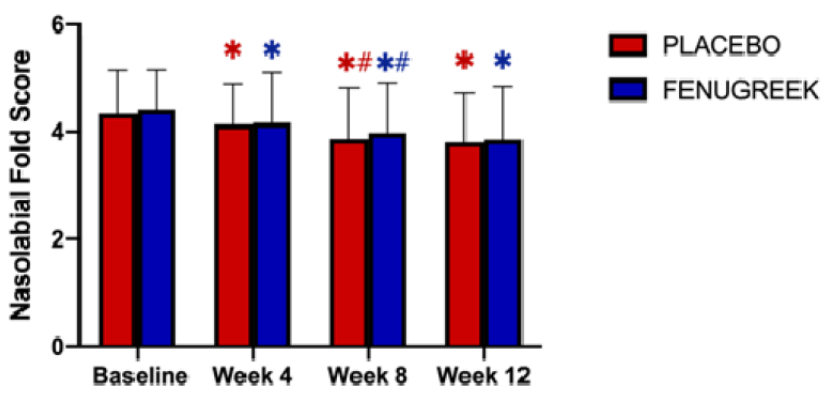

Figure 3. Forehead wrinkle, crow's feet, and nasolabial fold scores at baseline, 4th week, 8th week, and 12th week. Data are presented as mean (standard deviation). Unpaired $t$-test was used to analyze differences between the two groups. *Statistically significant difference with baseline $(\mathrm{p}<0.05)$; ${ }^{*}$ statistically significant difference with 4 th week $(p<0.05)$; ${ }^{a}$ statistically significant difference with 8 th week $(p<0.05)$.

Table 2. Score differences between baseline and time points.

\begin{tabular}{|c|c|c|c|}
\hline Time point & Placebo & Fenugreek & $p$-value \\
\hline \multicolumn{4}{|c|}{ Score difference (forehead wrinkle) } \\
\hline \multicolumn{4}{|c|}{ mean (SD) } \\
\hline 4th week & $0.44(0.58)$ & $0.37(0.49)$ & 0.8 \\
\hline 8th week & $0.64(0.70)$ & $0.50(0.59)$ & 0.5 \\
\hline 12 th week & $0.2(0.68)$ & $0.58(0.58)$ & 0.45 \\
\hline \multicolumn{4}{|c|}{ Score difference (crow's feet) } \\
\hline \multicolumn{4}{|c|}{ mean (SD) } \\
\hline 4th week & $0.20(0.38)$ & $0.35(0.43)$ & 0.190 \\
\hline 8 th week & $0.52(0.49)$ & $0.63(0.63)$ & 0.517 \\
\hline 12th week & $0.72(0.52)$ & $0.79(0.71)$ & 0.69 \\
\hline \multicolumn{4}{|c|}{ Score difference (nasolabial fold) } \\
\hline \multicolumn{4}{|c|}{ mean (SD) } \\
\hline 4th week & $0.32(0.02)$ & $0.25(0.53)$ & 0.69 \\
\hline 8th week & $0.48(0.53)$ & $0.44(0.65)$ & 0.80 \\
\hline 12th week & $0.54(0.58)$ & $0.56(0.73)$ & 0.90 \\
\hline
\end{tabular}

\section{DISCUSSION}

This study was an extension of the previous in vitro study conducted to determine the effect of fenugreek extract exposure on the secretion of COL1A1 and COL3A1 from the human dermal fibroblast culture (Yusharyahya et al., 2019; Yusharyahya et al., 2020). The average age of menopause was 49.5 years in the fenugreek group and 49.6 years in the placebo group. These findings are in accordance with the average age of menopause for 
Table 3. Dermal thickness difference between groups at time points.

\begin{tabular}{cccc}
\hline Time point & Dermal thickness placebo & Difference fenugreek & $\boldsymbol{p}$-value \\
\hline 4th week & $0.02(0.18)$ & $0.02(0.14)$ & \\
8th week & $0.06(0.18)$ & $0.07(0.18)$ & 0.946 \\
12th week & $0.03(0.17)$ & $0.01(0.14)$ & 0.607 \\
\hline
\end{tabular}

Data are presented as mean (standard deviation). Paired $t$-test was used to analyze differences between the two groups.

Table 4. Participants' compliance of cream application.

\begin{tabular}{|c|c|c|c|c|c|}
\hline Time point & $\begin{array}{c}\text { Level of } \\
\text { compliance }\end{array}$ & Placebo & Fenugreek & Total & $p$-value \\
\hline & & $n(\%)$ & $n(\%)$ & $n(\%)$ & \\
\hline \multirow[t]{3}{*}{ 4th week } & Good & $19(38.77)$ & $21(42.86)$ & $40(81.63)$ & 0.463 \\
\hline & Moderate & $6(12,24)$ & $3(6.12)$ & $9(18.37)$ & \\
\hline & Total & $25(51)$ & $24(49)$ & 49 (100) & \\
\hline \multirow[t]{3}{*}{ 8th week } & Good & $22(44.89)$ & $19(38.77)$ & $41(83.67)$ & 0.463 \\
\hline & Moderate & $3(6.12)$ & $5(10.2)$ & $8(16.33)$ & \\
\hline & Total & $25(51)$ & $24(49)$ & 49 (100) & \\
\hline \multirow[t]{2}{*}{12 th week } & Good & $25(51)$ & $24(49)$ & 49 (100) & 1 \\
\hline & Total & $25(1)$ & $24(49)$ & $49(100)$ & \\
\hline
\end{tabular}

Table 5. The side effects of cream application.

\begin{tabular}{cccccc}
\hline Timepoint & Side effects & Placebo $\boldsymbol{n}(\mathbf{\%})$ & Fenugreek $\boldsymbol{n}(\mathbf{\%})$ & Total & $\boldsymbol{p}$-value \\
\hline 4th week & None & $20(80)$ & $15(62.5)$ & $35(71.5)$ & 1 \\
& Pruritus & $5(20)$ & $9(37.5)$ & $14(28.57)$ & 0.217 \\
& Total & $25(100)$ & $24(100)$ & $49(100)$ & $49(100)$ \\
8th week & None & $25(100)$ & $24(100)$ & $49(100)$ & 1 \\
& Total & $25(100)$ & $24(100)$ & $43(87.76)$ & 1 \\
\hline
\end{tabular}

Table 6. Participants' satisfaction with fenugreek and placebo topical cream.

\begin{tabular}{ccccc}
\hline Satisfaction & Placebo & Fenugreek & Total & $\boldsymbol{p}$-value \\
\hline Satisfied & $\boldsymbol{n}(\boldsymbol{\%})$ & $\boldsymbol{n}(\boldsymbol{\%})$ & $\boldsymbol{n}(\boldsymbol{\%})$ & 0.72 \\
Not satisfied & $20(40.8)$ & $21(42.9)$ & $41(83.7)$ & $8(16.3)$ \\
Total & $5(10.2)$ & $3(6.1)$ & $49(100)$ & \\
\hline
\end{tabular}

Indonesian women, which is around 48-51 years (World Health Organization, 2015). The average age of menopause varies slightly in different countries: in India, the average age of menopause is around 46.2 years and in the UK 51 years, while in the US, it is 52.54 years (Ahuja, 2016; Gold, 2011; Yashvee et al., 2018).
The effects of fenugreek cream on skin wrinkles and dermal thickness

We observed improvement in skin wrinkles and dermal thickness in both fenugreek and placebo groups. However, there was no significant disparity between the two groups. This finding 


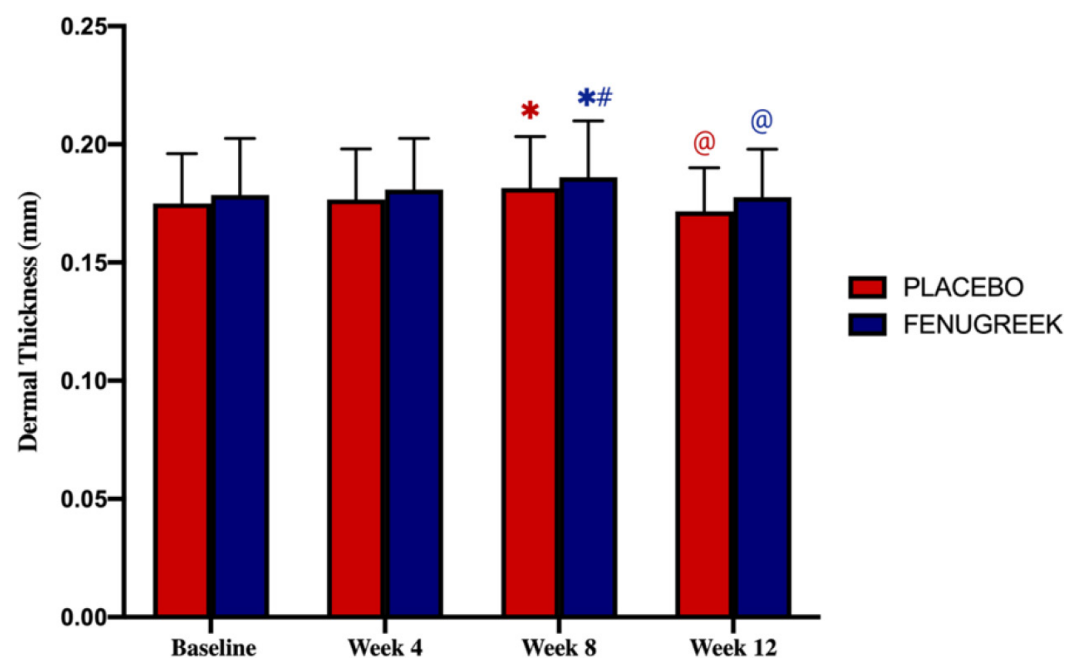

Figure 4. Dermal thickness at baseline, 4th week, 8th week, and 12th week.

Data are presented as mean (standard deviation). Unpaired $t$-test was used to analyze differences between the two groups. "Statistically significant difference with baseline $(p<0.05)$; ${ }^{\text {\#}}$ statistically significant difference with 4 th week $(p<0.05)$; ${ }^{\circledR}$ statistically significant difference with 8 th week $(p<0.05)$.

concluded that the $5 \%$ concentration in the fenugreek cream might be inadequate to reduce wrinkles and does not represent the optimum concentration to increase dermal thickness.

Collagen plays a role in skin aging, but until now, the pathogenesis of wrinkles is yet to be fully comprehended (Baumann, 2007). The fenugreek cream in this study was found to be inadequate to reduce skin wrinkles through a hypothesized pathway of increasing COL1A1 and COL3A1 in the dermis, and therefore the improvement in wrinkle scores might occur only because of the moisturizing effects of the base cream, which increased dermal water content. The base cream (placebo) used in this study contained ketosteril alcohol, paraffin liquidum, propanediol, and glycerin, which possess humectant and emollient properties so that it acts as moisturizer capable of increasing water capacity in the stratum corneum and filling spaces between corneocytes. Thus, corneocytes become swollen, and cell thickness increases, manifesting in a smoother surface and less apparent facial wrinkles.

The in vivo results for dermal thickness did not support our previous in vitro finding, which demonstrated that fenugreek extract's ability to significantly increase collagen secretion compared to control in the fibroblast of a postmenopausal woman (Yusharyahya et al., 2019). Until recently, there has been no formula to convert in vitro-in vivo formulation, and therefore the optimum concentration observed in vitro $(2 \mu \mathrm{g} / \mathrm{ml})$ could not be converted into the optimum concentration in vivo. Furthermore, the active components on which we placed utmost importance in this study were orientin, despite other possible active compounds found in fenugreek (sapogenin steroid, alkaloid, flavonoid, amino acid "4-hydroxyisoleucine") which may also influence the skin with their agonist or antagonist effect toward ER (ER $\alpha$ and ER B) (Yusharyahya et al., 2019). Mlosek et al. (2013) provided a possible explanation for the lack of disparity in dermal thickness between fenugreek cream and placebo, whose study reported that the application of a cream containing emollient was able to improve dermal thickness by $6 \%$ compared to baseline after 2 weeks (Mlosek et al., 2013). No previous research has been conducted on the effect of fenugreek extract on dermal thickness. Given an optimal concentration, fenugreek cream can plausibly increase dermal collagen.

The reduction of dermal thickness in week 12 compared to week 8 might be due to several plausibilities. Each postmenopausal woman included in this study had experienced low estrogen levels for several years differently. Thus, it could affect estrogen therapy since it is related to the initial collagen content (Stevenson and Thornton, 2007). Another plausibility is due to changes in collagen type III/type I ratio. Although phytoestrogen stimulates the increase of dermal thickness, depletion of collagen type III/type I ratio within the dermis also occurs simultaneously in postmenopausal women (Affinito et al., 1999).

Although the experimental group showed a statistically insignificant difference compared to the placebo group in reducing wrinkles and increasing dermal thickness, we proposed a mechanism of how fenugreek reduces skin wrinkles and improves dermal thickness in treated women, if skin biopsy was carried out, as shown in Figure 5. The epidermal corneocytes on the baseline (A) were small in size and the epidermal surface was uneven. It was visibly seen as rough/dry skin and wrinkly. The application of 5\% fenugreek cream (B) could penetrate into epidermis and dermis. After 8 weeks of application, the fenugreek cream could increase the water content in the epidermis, resulting in the corneocytes to bind with water and swell (enlarged in size) causing a smoother epidermal surface, as well as moist skin in wrinkles. Moreover, the amount of collagen increased in the dermis, also resulting in a smoother epidermal, thicker, and denser dermal layer which was clinically seen as reduced wrinkles on the skin.

\section{The compliance and side effects}

The assessment of the participant compliance showed that most participants from both groups were highly compliant. The 

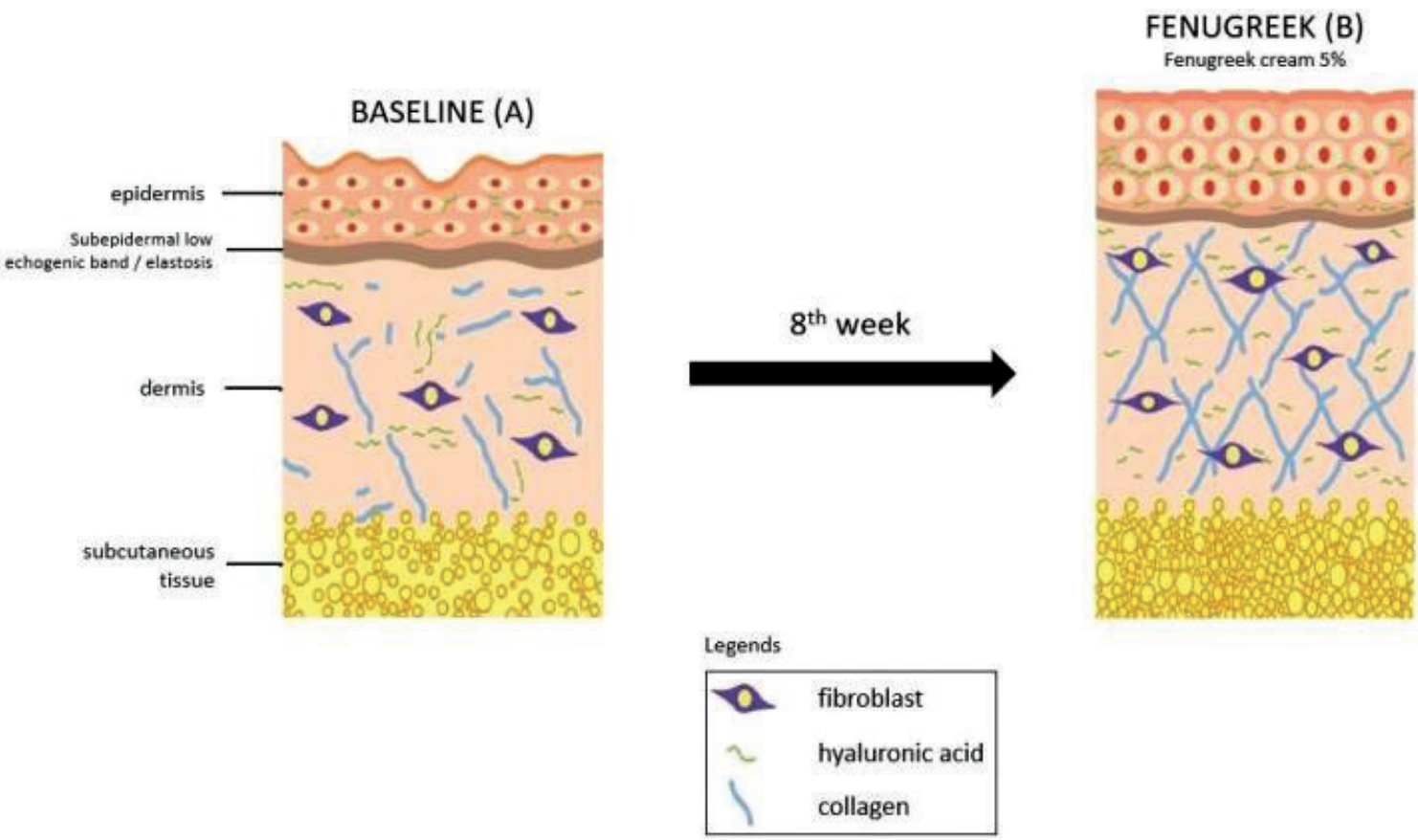

Figure 5. The proposed pathophysiology changes of skin improvement for postmenopausal women given fenugreek cream.

proportion of highly compliant participants improved in the 8th and 12 th weeks. The motivation to appear younger with minimal side effects was the drive for this high rate of compliance. Although the daily evaluation was carried out through the participants' written journal and weighing the remaining used cream to reduce bias, the compliance of cream application relied solely on each participant, and it did not vary significantly between both groups.

Mild pruritus was experienced by some of the participants as a side effect but there was no significant difference between both groups. This side effect did not disrupt daily activities and cause any dropouts. There were no other local nor systemic side effects reported from both groups. No clinical studies were found regarding the side effects of the fenugreek cream; however, a study by Muralidhara et al. (1999) was conducted using intragastric administration of debitterized fenugreek on adult mice and rats. The results showed no signs of acute nor subchronic toxicity and no animal died (Muralidhara et al., 1999). Moreover, estrogen topical cream is still used to treat aging skin, but several studies by Schmidt et al. (1996), Simon et al., (2007), and Creidi et al. (1994) demonstrated more severe side effects of the topical formulations, such as irritation, pruritus, headache, nausea, vomiting, breast pain, vaginal bleeding, and endometrial thickening. Based on the mentioned side effects, further research on fenugreek cream should be conducted to replace estrogenic topical cream to treat aging skin in postmenopausal women as it is found to have milder side effects.

\section{Participant satisfaction}

There was no significant difference between the two groups regarding the participants' satisfaction. The reason may be due to the ingredients of both topical creams: the inadequate concentration of the fenugreek cream and the humectant and emollient-based cream for the placebo that may give a false result in reducing facial wrinkles.

\section{Limitations}

One of the limitations of this study is that only one concentration was assessed which was then evidently inadequate. The concentration of the fenugreek cream was chosen to be at $5 \%$, slightly higher than the previous studies by Waqas et al. (2010) and Naveed et al. (2010) that used 4\% concentration which demonstrated its benefits toward skin elasticity, moisture, and melanin concentration. In addition, the fenugreek extraction method used in this study was also different from those former studies. Waqas et al. (2010) purchased the extract directly from a local shop, while Naveed et al. (2010) used $80 \%$ of methanol.

The other limitation of this study is the base cream (placebo) used in this study contained other substances, such as ketosteril alcohol, paraffin liquidum, propanediol, and glycerin which act as a moisturizer since they have the capability of increasing water capacity in the stratum corneum and filling spaces between corneocytes.

Another limitation is the small sample size. With a small sample size, it was challenging to conclude whether the fenugreek topical cream was evidently ineffective, or the sample size was simply too small. It is hoped that further research could be conducted with a larger sample size to reduce bias.

\section{CONCLUSION}

Both 5\% fenugreek cream and base cream showed improvement in reducing wrinkles and increasing dermal thickness. Although we did not achieve a statistically significant difference in the improvement between the two groups in the in vivo study, based on the previous in vitro study, it is still hopeful that the fenugreek topical formulation can still stand as a potential 
antiaging therapy given a more appropriate concentration. Further research using a more extensive range of concentration levels with larger sample size is required to observe the effectivity of fenugreek cream toward skin wrinkle and dermal thickness to permit clinical use.

\section{ACKNOWLEDGMENTS}

The authors would like to thank Dr. Stephen Akihiro, SpDV, for editing and proofreading the manuscript. They would also like to thank the research unit of Dr. Cipto Mangunkusumo Hospital (Hibah penelitian, 2019) for supporting the pilot study as well as Universitas Indonesia for funding this research through PUTI Grant with contract number NKB-4456/UN2.RST/ HKP.05.00/2020.

\section{AUTHOR CONTRIBUTIONS}

All authors made substantial contributions to conception and design, acquisition of data, or analysis and interpretation of data; took part in drafting the article or revising it critically for important intellectual content; agreed to submit to the current journal; gave final approval of the version to be published; and agree to be accountable for all aspects of the work. All the authors are eligible to be an author as per the international committee of medical journal editors (ICMJE) requirements/guidelines.

\section{CONFLICTS OF INTEREST}

The authors report no financial or any other conflicts of interest in this work.

\section{PUBLISHER'S NOTE}

This journal remains neutral with regard to jurisdictional claims in published institutional affiliation.

\section{REFERENCES}

Affinito P, Palomba S, Sorrentino C, Di Carlo C, Bifulco G, Arienzo M. Effects of postmenopausal hypoestrogenism on skin collagen. Maturitas, 1999; 33:239-47.

Agustini K. Isolasi dan karakterisasi senyawa aktif serta eksplorasi aktivitas in vitro dan in vivo biji klabet (Trigonella foenum graecum L.) sebagai SERMs (selective estrogen receptor modulators) alamiah. Indones J Pharm, 2012; 11:13-20.

Ahuja M. Age of menopause and determinants of menopause age: a PAN India survey by IMS. J Midlife Health, 2016; 7:126-31.

Badan Pusat Statistik. Indikator strategis nasional [ONLINE]

Badan Pusat Statistik, 2019. Available via https://www.bps.go.id/ QuickMap?id= 0000000000 (Accessed July 2020) 211:241-51.

Baumann L. Skin ageing and its treatment. J Pathol, 2007;

Bazin R, Flament F. Skin aging atlas. Medcom, Paris, France, 2010.

Creidi P, Faivre B, Agache P, Richard E, Haudiquet V, Sauvanet JP. Effect of a conjugated oestrogen (premarin) cream on ageing facial skin. A comparative study with a placebo cream. Maturitas, 1994; 19:211-23.

Gold EB. The timing of the age at which natural menopause occurs. Obstet Gynecol Clin North Am, 2011; 38:425-40.

Gade J, More S, Bhalerao N. Formulation and characterization of herbal cream containing fenugreek seed extracts. Int J Sci Res, 2015; $5: 2250-5$.

Kapuscinska A, Nowak I. The use of phytoestrogens in anti-ageing cosmetics. Chemik, 2015; 69:154-59.
Malaivijitnond S. Medical applications of phytoestrogens from the thai herb pueraria mirifica. Front Med, 2012; 6:8-21.

Manela-Azulay M, Bagatin E. Cosmeceuticals vitamins. Clin Dermatol, 2009; 27:469-74.

Mlosek RK, Malinowska S, Sikora M, Dębowska R, Stępień A, Czekaj K, Dąbrowska A. The use of high frequency ultrasound imaging in skin moisturization measurement. Skin Res Technol, 2013; 19:169-75.

Muralidhara K. Viswanatha NS, Ramesh BS. Acute and subchronic toxicity assessment of debitterized fenugreek powder in the mouse and rat. Food Chem Toxicol, 1999; 37:831-8.

Naveed A, Waqas MK, Ahmad M, Saeed T, Murtaza G, Rasool A, Aamir MN, Khan S, Bhatti NS, Ali A. Effect of cream formulation of fenugreek seed extract on some mechanical parameters of human skin. Trop J Pharm Res, 2010; 9:329-37.

Piérard G E, Humbert P, Berardesca E, Gaspard U, Hermanns-Lê T, Piérard-Franchimont C. Revisiting the cutaneous impact of oral hormone replacement therapy. Biomed Res Int, 2013; 2013:971760-60.

Schmidt JB, Binder M, Demschik G, Bieglmayer C, Reiner A. Treatment of skin aging with topical estrogens. Int J Dermatol, 1996; 35:669-74.

Simon JA. Estradiol topical emulsion for the treatment of moderate-to-severe vasomotor symptoms associated with menopause. Womens Health (Lond), 2007; 3:29-7.

Stevenson S, Thornton J. Effect of estrogens on skin aging and the potential role of SERMs. Clin Interv Aging, 2007; 2:283-97.

Thornton MJ. The biological actions of estrogens on skin. Exp Dermatol, 2002;11:487-502.

Waqas MK, Akhtar N, Ahmad M, Murtaza G, Khan HM, Iqbal M, Rasul A, Bhatti NS. Formulation and characterization of a cream containing extract of fenugreek seeds. Acta Pol Pharm, 2010; 67:173-8.

World Health Organization. Indonesia country profile [ONLINE]. WHO, Geneva, Switzerland, 2015. Available via http://www. who.int/countries/idn/en/ (Accessed July 2020)

Yashvee, Greenwood DC, Burley VJ, Cade JE. Dietary intake and age at natural menopause: results from the UK Women's Cohort Study. J Epidemial Community Health, 2018; 72:733-40.

Yusharyahya SN, Bramono K, Hestiantoro A, Edwar SQ, Kusuma I. Fenugreek (Trigonella foenum-graceum) increases postmenopausal fibroblast-associated COL1A1 and COL3A1 production dominantly through its binding to estrogen receptor beta. J Appl Pharm Sci, $2020 ; 10: 22-7$.

Yusharyahya SN, Bramono K, Ascobat P, Hestiantoro A, Sutanto NR, Fadilah F. In silico molecular docking and pharmacophore modelling studies of Trigonella foenum-graceum (fenugreek) interactions with estrogen receptors $\alpha$ and $\beta$. J Pharm Sci Res, 2019a; 11:3705-11.

Yusharyahya SN, Bramono K, Sutanto NR, Kusuma I. The effect of Trigonella foenum-graceum L. (fenugreek) toward collagen type I alpha 1 (COL1A1) and collagen type III alpha 1 (COL3A1) on postmenopausal woman's fibroblast. Nat Prod Sci, 2019b; 25:208-14.

Zhang J, Hou W, Feng S, Chen X, Wang H. Classification of facial wrinkles among Chinese women. J Biomed Res, 2017; 31:108-15.

How to cite this article:

Yusharyahya SN, Bramono K, Indriatmi W, Prasetyo M, Ascobat P, Hestiantoro A, Wiraguna AAGP. Anti-aging effects of fenugreek cream on postmenopausal skin: A randomized controlled trial. J Appl Pharm Sci, 2021; 11(11):095-103. 